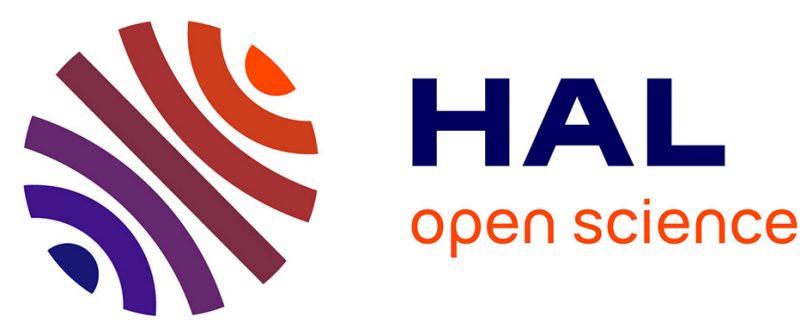

\title{
Publishing Authentic, Private, Personal Data About Service Quality of Healthcare for Pain
}

Peter Pennefather, West Suhanic, Fatima Lakha, Deborah I Fels

\section{To cite this version:}

Peter Pennefather, West Suhanic, Fatima Lakha, Deborah I Fels. Publishing Authentic, Private, Personal Data About Service Quality of Healthcare for Pain. ELPUB 2018, Jun 2018, Toronto, Canada. 10.4000/proceedings.elpub.2018.15 . hal-01816653

\section{HAL Id: hal-01816653 https://hal.science/hal-01816653}

Submitted on 15 Jun 2018

HAL is a multi-disciplinary open access archive for the deposit and dissemination of scientific research documents, whether they are published or not. The documents may come from teaching and research institutions in France or abroad, or from public or private research centers.
L'archive ouverte pluridisciplinaire HAL, est destinée au dépôt et à la diffusion de documents scientifiques de niveau recherche, publiés ou non, émanant des établissements d'enseignement et de recherche français ou étrangers, des laboratoires publics ou privés. 


\title{
Publishing Authentic, Private, Personal Data About Service Quality of Healthcare for Pain
}

\author{
Peter Pennefather, West Suhanic, Fatima Lakha and Deborah I. Fels
}

\section{Introduction}

1 We are developing a general strategy for registering patient authored, curated and owned private healthcare data for anchoring patient-oriented quantitative and qualitative measurement of the impact and quality of that medical care (Pennefather et al., 2018, Fels et al., 2018). This strategy is implemented by allowing patients to store personal data records as self-referencing, self-authenticating units within a scalable and encrypted format (Pennefather and Suhanic, 2016, 2017). That format facilitates indexing, analyzing and publicaly pooling data derived from the private data within distributed ledgers (Kuo et al., 2017; Roehrs et al., 2017).

2 To specify the design, we use the case of registering the contents of unstructured digital scrapbooks (Fels et al., 2018) about care patients experience for medically significant pain and distress. Those affective states become medically significant when associated with suffering warranting medically supervised interventions. Otherwise, the states are normal, driving adaptive behaviour beneficial to the individual. Excessive negative salience transforms normal responses into medically significant cases, and needs to be understood from the patients perspective (Williams, 2017).

Using the lens of inclusive design, we discuss the value of deriving and publicly sharing data from private personal data repositories governed and owned by the patient and concerning how they experience their options, conditions and care. This is followed by a conceptual synthesis and a design specification based on an inclusive systemic design goal. That goal is to link a patient's personal self-reported data to medical records about that patient. Implications of the design for creating a new common pool resource (CPR; Ostrom and Hess, 2010) of derived personal health data is described. We discuss how that 
resource could support new media for evaluating, modelling and reporting on determinants of health and healthcare outputs and outcomes.

\section{Documenting Medical Pain Care}

4 Analysis of administrative and census data suggests that in Ontario, in any one year, $10-20 \%$ of the adult population suffer chronic pain and/or debilitating distress and costs the health system twice as much as matched controls (Hogan et al. 2016; Chiu et al., 2017). Documentation is an essential component of any reliable, effective and accountable healthcare management system. However, given the individuated nature of pain care, pre-structured health record formats are poorly suited for managing impact that care on reducing personally experienced pain while satisfactorily achieving individuated goals set by patients (Clark, 2002; Watkins et al., 2003).

5 Patient input is necessary, but data comprised of subjective impressions recorded by patients tend to exhibit self-representation bias. We suggest that this bias can be reduced by triangulating between structured and unstructured data (Hall and Caton 2017) derived from measures of traits and orientations (Hutta, 2016; Nilsson, 2013). New methods are emerging for measuring personality data (i.e. sets of consistent traits, orientations, behaviours, attitudes, and emotions specific to individuals) from analysis of large unstructured volumes of videos (Tay et al., (2017) or analysis of language use (Boyd and Pennebarker, 2017).

6 Emerging recognition of the construct-measurement distinction (Sackett et al. 2017) and of distinctions between stable personality traits and dynamic temperament traits (Trofimova et al., 2017) points to the challenges of accounting for individual differences in terms of objectively measured traits and orientations. However, those insights also suggests to us that data derived unobtrusively from patient curated digital scrapbook data (Fels et al, 2018) could be useful in qualifying and classifying pain patient reports concerning their suffering and their care, in ways that relate contents of those reports to stable personality drivers.

7 Such an analysis could help the health system learn how to deal with the context dependence of the quality and outcomes of care for medically significant suffering. That context dependence reflects interactions between human factors (biology, cognition and behaviour), as well as environmental factors (sociological, economic, cultural and natural) (Opsina et al., 2013; Wagner et al., 2013).

This is leading to a re-evaluation of pain from being primarily identified as nociception to being more precisely identified as a distressful experience associated with the perceived negative salience of that experience (Williams, 2017). Suffering associated with that negative affect is the principle debilitating symptom for affective disorders in general and can be managed using a range of both medical and non-medical therapies (Williams, 2017; Williams, 2017, Wagner et al., 2013). Those therapies modulate personal and context dependent affect but, this does not mean that the physical body and its biology are irrelevant. For example, behavioural interventions leading to placebo analgesia are blocked by cannabinoid and opiate receptor antagonist (Schafer et al., 2018), reflecting, perhaps, interactions between measures of biological temperament and psychological personality (Trofimova et al., 2018). 
We therefore believe that it will be useful to document and triangulate individual and dynamic symptom differences, in an inclusive patient-centred manner, by linking system level documentation with patient curated reports of their experiences with health system care. Emerging frameworks supporting unobtrusive analysis of large volumes of unstructured data open up new ways for achieving that goal.

\section{Design Synthesis \& Specification}

We have three design goals:

1. for the proposed derived data pooling system is to enable patients to privately author and curate authentic, personal, experiential, reflective data on their medically significant pain and distress, and on how they are coping with medical care for those conditions;

2. to make that data accessible to analytical agents that can generate and pool new public data derived from that private personal data for various registered purposes; and

3. to host and oversee this derived data common pool within a system of distributed governance that benefits the persons the data are about, as well as a diverse variety of other health system actors and stakeholders.

11 Here we frame inclusive systemic design constraints to specify such a data pooling process. Systemic design invokes systemic views of complex system problems in ways addressable by intuitive and abductive approaches implicit in design thinking (Jones, 2014). Inclusive designs feature three dimensions:

1. recognition of diversity and uniqueness of users;

2. inclusion of broad ranging processes and tools; and

3. broad beneficial impacts (Pullin et al., 2017).

12 Our design strategy also is informed by the social-ecological-system framework for evaluating resource governance procedures (Ostrom and Hess, 2010). That framing distinguishes between governance of four type of resources: private, public, toll-goods and common pool resources (CPR), based on levels of two attributes:

1. excludability,

2. subtractability.

13 Excludability refers to the degree of ease of excluding others from using a resource, while subtractabilty refers to the extent that use of a resource by one stakeholder reduces access to the resource by other users. Non-excludable ressources, that must be accessed by all, are classified as a commons. When those commons have low subtractibility they are considered a public good, like large oceans. But, when use of the resource can cause rivalries, due to usage-capacity limits, as in small lakes, there is high subtractability and the ressource is called a common-pool resource (CPR) (Hiller and Shakelford, 2018).

14 Fisher and Fortman (2010) have suggested that, in general, digital data should not be considered a CPR because digital data is easily copied and therefore has limited subtractibility. However, unlike digital data per se, access to personal data, and even to data derived from that personal data, always must be limited if personal privacy is to be respected (Ohms 2010). Persons who the data are about can benefit or be harmed by how personal data are used in representing them. Nevertheless, providing safe, dignified, unobtrusive and limited access to that data can help the health system in developing a 
patient oriented view on patient services provided by that system. In that sense data derived from private personal data can be considered a CPR.

Building on the observation that a collaborative poly-centric governance framework seems to work best in managing CPRs (Hiller and Shakelford, 2018; Smith, 2017), our design strategy builds on the idea that the challenged of publicly sharing data derived from private personal data is less about data anonymization and more about ensuring personal agency and sovereignty over how private personal data are used (Ohm, 2010). Cyber-security tools for encrypting personal data are effective alternative to anonymization for protecting personal privacy (Landau, 2017). Hash-function unique identifiers, a basic element of such tools, have the added benefit of facilitating the logging, oversight and management of data use (Landau, 2017).

The design is enabled by gDial Inc. technology for transforming any from of data into selfreferencing, self-authenticating data quanta (see, Pennefather et al., 2018; Pennefather and Suhanic, 2016, 2017). That atomization makes the personal data tangible and extends personal property laws from the data storage medium to the bytes of data stored in that medium. Even though the data is owned by and in the custody of patients, it can still be seen as authentic evidence. The patient curates and accessions data, but cannot modify it after its registration. This also allows this evidence to be cited even if placed behind a privacy wall using data citation systems (McMurray et al, 2017).

Although we have evidence that authoring and curating reflective self-referencing data has an intrinsic personal utility (Fels et al, 2018), greater systemic utility might be gained for the health system, and society at large, if these personal data could be linked to analogous data located elsewhere in the system. For example, patient access to their EMR data, and data of others who trust them, now can be achieved easily using FHIR (Fast Health Interoperability Resource) protocols and patient portals (Kuo et al., 2017; Rohrs et al., 2017). This opens a path to linking data through repatriation of system data around the individuals the data is about. Patients can then authorize aggregation of institutional personal data into CPRs for purposes the patients supports.

There also is an increasing receptiveness, in the health record industry, to use distributed ledger technology to trial new business models around federating administrative data linked to particular individuals in a way that can provide continuously updated access to data on all patients served by consortium members (Business Wire, 2018). These data lakes are now recognized as valuable resources that can train machine learning algorithms in enhancing health system outputs and outcomes (Momoshina et al., 2018).

By analogy with clinical trial registries and their purpose of linking clinical trials to published results (see Bashir, 2017), inputs into big data training sets used for healthrelated decision support need to be publicly vetted, if only to detected confirmation bias associated with algorithmic intelligence applications (Galliers et al. 2018). Data atomization allows data provenance to be traced so that specific training sets can be tested for bias and consistency.

20 Many considerations need to be analyzed in order for this design strategy to be realized, including:

1. how data can be securely entered by participants,

2. frequency and method of data collection and derivation,

3. possible data types, and

4. methods for analyzing and reporting on these data. 
21

In addition, the different insights of different stakeholders into what are meaningful and useful outcomes of that analysis and reporting that must recognized and used to govern choices in a respectful polycentric manner.

Many types of data analytic innovations can now be applied to meet those needs. These include:

1. multi-modal sentiment and affect analyses (Soleymani et al., 2017),

2. speech analysis,

3. big-data pattern recognition and outlier identification algorithms (Gruber et al., 2017), and

4. data visualization techniques (Zhu et al., 2017).

These data analaytic innovations can also be applied to make the polycentric governance process evident. The broad strokes of our design specification are then:

1. atomizing raw private data,

2. providing limited access to that private data for regsitered purposes to agents that can algorithmically process that private data into derived raw data,

3. making that derived raw data available as a public common pool resource with polycentric governance over its publication.

\section{Publishing Patient Reported Data}

We have described a design strategy for allowing patient reported experiences to be translated into self-authenticating, registered, derived data records that can be indexed and mined as a common pool resource. Like census data, that resource can be mined by scholars and health system stakeholders, including patients, to anchor systematic analysis of determinants of health and of health-care outcomes and outputs. We suggest that publication of descriptions of those analytic studies can form the basis of a new medium for sharing patient-oriented scholarly and administrative medical research and analysis. This is important because in medicine, data concerning knowledge and attitudes of all involved in a therapy need to be coherently integrated in the evaluation of the skills and practices applied within the evaluated care regime for that appraisal to be meaningfully authentic (Petraglia, 2009).

\section{BIBLIOGRAPHY}

\section{References}

Bashir, R., Bourgeois, F.T., \& Dunn, A.G. (2017). “A systematic review of the processes used to link clinical trial registrations to their published results." Systematic Reviews, 6. https:// doi.org/10.1186/s13643-017-0518-3 
Boyd, R. L., \& Pennebaker, J. W. (2017). “Language-based personality: A new approach to personality in a digital world." Curr. Opinion in Behavioral Sciences, 8: 63-68.

Business Wire (2018). Humana, Multiplan, Optum, Quest Diagnostics and United Healthcare launch blockchain driven effort to tackle care provider data issues. (Retr. 25/04/18) https:// www.businesswire.com/news/home/20180402005181

Clark, J.D. (2002). “Chronic pain prevalence and analgesic prescribing in a general medical population.” Journal of Pain Symptom Management. 23: 131-137.

Chiu, M., Lebenbaum, M., Cheng, J., de Oliveira, C., \& Kurdyak, P. (2017). “The direct healthcare costs associated with psychological distress and major depression.” PLOS ONE 12: e0184268.

Fels, D.I., Lakha, S.F., Holtzman, C.B., Khandwala, A., Whitfield, M., Suhanic, W., \& Pennefather, P. (2018). "Videobooking: A person-centred record of living with chronic conditions and associated disabilities." ICCHP2018. Lintz.

Fisher, J.B., \& Fortmann, L. (2010). "Governing the data commons: Policy, practice, and the advancement of science." Information and Management, 47: 237-245.

Galliers, R. D., Newell, S., Shanks, G., \& Topi, H. (2017). "Datification and its human, organizational and societal effects.” J. Strategic Information Systems, 26: 185-190.

Gruber, W.H., Powell, A. C., \& Torous, J.B. (2017). "The power of capturing and using information at the point of care." Healthcare, 5: 86-88.

Hall, M., \& Caton, S. (2017). “Am I who I say I am? unobtrusive self-representation and personality recognition on Facebook.” PLoS ONE, 12: e1371.

Hiller, J. S., \& Shackelford, S. J. (2018). "The firm and common pool resource theory: Understanding the rise of benefit corporations.” Am. Business Law Journal, 55: 5-51.

Hogan, M., Taddio, A., Katz, J., Shah, V., Krahn, M. (2016). "Incremental health care costs for chronic pain in Ontario, Canada." Pain, 157: 1626-1633.

Huta, V. (2016). "Eudaimonic and hedonic orientations: Theoretical considerations and research findings.” In J. Vittersø (Ed.), Handbook of Eudaimonic Well-being, 215-231. Switzerland: Springer.

Jones, P. H. (2014a). "Systemic design principles for complex social systems." In Metcalf, G. S. (Ed). (2014). Social Systems and Design, Translational Systems Sciences 1, 91-128. Tokyo, JP: Springer.

Kuo, T. -., Kim, H. -., \& Ohno-Machado, L. (2017). "Blockchain distributed ledger technologies for biomedical and health care applications." JAMIA, 24: 1211-1220.

Landau, S. (2017). Listening in: Cybersecurity in an Insecure Age. Yale, NH: University Press.

Mamoshina, P., Ojomoko, L., Yanovich, Y., Ostrovski, A., Botezatu, A., Prikhodko, P., Zhavoronkov, A. (2018). "Converging blockchain and next-generation artificial intelligence technologies to decentralize and accelerate biomedical research and healthcare." Oncotarget, 9: 5665-90.

McMurry, J.A., Juty, N., Blomberg, N., Burdett, T., Conlin, T., Conte, N., Parkinson, H. (2017). "Identifiers for the 21st century: How to design, provision, and reuse persistent identifiers to maximize utility and impact of life science data." PLoS Biology, 15: 1371.

Nilsson, A. (2014). "Personality psychology as the integrative study of traits and worldviews," New Ideas in Psychology, 32: 18-32.

Ohm, P. (2010). "Broken promises of privacy: Responding to the surprising failure of anonymization." UCLA Law Review, 57: 1701-1777. 
Ospina, M.B., Taenzer, P., Rashiq, S., MacDermid, J.C., Carr, E., Chojecki, D., Henry, J.L. (2013). “A systematic review of the effectiveness of knowledge translation interventions for chronic noncancer pain management." Pain Research and Management, 18: 129-141.

Ostrom, E., \& Hess, C. (2010). "Private and common property rights." In Bouckaert, B. (Ed.). Property law and economics vol. 5, 55-106. Edward Elgar Publishing.

Pennefather, P. \& Suhanic, W., (2016). Systems and methods for authenticating and aiding in indexing of and searching for electronic files. https://patents.google.com/patent/US9465858

Pennefather. P., and \& Suhanic, W., (2017). Systems and methods for atomizing and individuating data as data quanta. https://patents.google.com/patent/US20160321316A1

Pennefather, P., Seaborn, K., \& Fels, D., (2018 in press). “Systemic design principles for promoting eudaimonic flourishing through the use of health-care flourishment records." In: Systemic Design, Jones P, Kijiima K (Eds.), London, UK: Springer, (in-press).

Petraglia, J. (2009). "The importance of being authentic: Persuasion, narration, and dialogue in health communication and education.” Health Communication, 24: 176-185.

Pullin, G., Treviranus, J., Patel, R., \& Higginbotham, J. (2017). “Designing interaction, voice, and inclusion in AAC research." Augmentative and Alt. Comm., 33: 139-148.

Roehrs, A., da Costa, C.A., \& da Rosa Righi, R. (2017). “OmniPHR: A distributed architecture model to integrate personal health records.” J Biomed Info, 71: 70-81.

Sackett, P.R., Lievens, F., Van Iddekinge, C.H., \& Kuncel, N.R. (2017). "Individual differences and their measurement: A review of 100 years of research.” Journal of Applied Psychology, 102: 254-273.

Schafer, S.M., Geuter, S. and Wager, T.D. (2018). "Mechanism of placebo analgesia: A dual process model informed by insights from cross-species comparisons.” Prog. Neurobio, 160: 101-122.

Smith, K. (2017). "Innovating for the global commons: multilateral collaboration in a polycentric world." Oxford Review of Economic Policy. 33: 49-65.

Soleymani, M., Garcia, D., Jou, B., Schuller, B., Chang, S. F., \& Pantic, M. (2017). “A survey of multimodal sentiment analysis." Image and Vision Computing, 65: 3-14.

Tay, L., Jebb, A.T., \& Woo, S.E. (2017). “Video capture of human behaviors: Toward a big data approach." Current Opinion in Behavioral Sciences, 18: 17-22.

Tengland, P.A. (2012). "Behavior change or empowerment: On the ethics of health-promotion strategies." Public Health Ethics, 5: 140-153.

Trofimova, I., Robbins, T.W., Sulis, W.H., \& Uher, J. (2018). “Taxonomies of psychological individual differences." Phil. Trans. Royal Soc. B: Bio. Sciences, 373: 1744.

Sackett, P.R., Lievens, F., Van Iddekinge, C.H., \& Kuncel, N.R. (2017). "Individual differences and their measurement: A review of 100 years of research." Journal of Applied Psychology, 102: 254-273.

Wagner, L.I., Spiegel, D., \& Pearman, T. (2013). "Using the science of psycho-social care to implement the new American College of Surgeons commission on cancer distress screening standard." JNCCN, 11: 214-221.

Watkins, A., Wasmann, S., Dodson, L., Hayes, M. (2004). “An evaluation of the care provided to patients prescribed controlled substances for chronic nonmalignant pain at an academic family medicine center." Fam Med. 36: 487-489.

Williams, A.C.D.C. (2017). "Patient action as means and end of chronic pain care: Risks and routes to meaningful action." Pain, 158: 1403-1404. 
Zhu, Z., Heng, B.H., \& Teow, K.L. (2017). “Interactive Data Visualization to Understand Data Better.” In Decision Management: Concepts, Methodologies, Tools, and Applications, 27-36. IGI Global.

\section{ABSTRACTS}

An inclusive systemic design is specified for publishing data derived from personal private health records, owned and curated by patients. The design is specified with an example of a digital scrapbook of private personal records of care for medically significant pain. This scrapbook is designed to aggregate private records of patient pain experiences and of the care and accommodations they access. The design also specifies how to store, access and analyze those private records through distributed ledgers and how qualitative and quantitative data derived from that private data can be published as a common pool resource with polycentric governance.

\section{INDEX}

Keywords: private health data, distributed ledgers, health data publication

\section{AUTHORS}

\section{PETER PENNEFATHER}

gDial Inc. and Dan Faculty of Pharmacy, University of Toronto, Toronto, Canada p.pennefather@gmail.com

(corresponding author)

\section{WEST SUHANIC}

gDial Inc., Toronto, Canada

w.suhanic@gmail.com

\section{FATIMA LAKHA}

Inclusive Media and Design Center. Ryerson University, Toronto, Canada shashafat@gmail.com

\section{DEBORAH I. FELS}

Inclusive Media and Design Center. Ryerson University, Toronto, Canada dfels@ryerson.ca 